\title{
Scale in education research: towards a multi-scale methodology
}

\author{
Andrew Noyes \\ University of Nottingham
}

\begin{abstract}
This article explores some theoretical and methodological problems concerned with scale in education research through a critique of a recent mixed-method project. The project was framed by scale metaphors drawn from the physical and earth sciences and I consider how recent thinking around scale, for example in ecosystems and human geography might offer helpful points and angles of view on the challenges of thinking spatially in education research. Working between the spatial metaphors of ecology scholars and the critiques of the human geographers, for example the hypercomplex social space in Lefebvre's politicaleconomic thinking and the fluid, simultaneous, multiple spatialities of Massey's post-structuralism, I problematize space and scale in education research. Interweaving these geographical ideas with Giddens' structuration and Bourdieu's theory of practice, both of which employed what might be termed scalebridging to challenge social science's entrenched paradigms, leads me to reconsider what is possible and desirable in the study of education systems. Following the spatial turn in the social sciences generally, there is an outstanding need to theorise multi-scale methodology for education research.
\end{abstract}

Keywords: scale, space, human geography, methodology

"a key to understanding the hierarchical structuring/patterning of complex systems...lies in understanding the 'nature' of scale...no single scale is sufficient for assessing the varying sized, and spatially arranged components on the planet, a society, or in any complex system.

Therefore, to appropriately monitor, model, and manage these environments a multi-scale (i.e., more than a single scale) approach is necessary" (Hay, 2005, p. 249)

There is no such thing as a scale (Thrift, 1995, p. 33) 


\section{Introduction: an initial conceptual framework}

Public education operates and is understood at different scales. Notwithstanding the recent debates in human geography regarding whether scale is an ontological or epistemological category (Brenner, 2001; Herod, 2011; Jones, 1998; Marston, 2000; Moore, 2008), compulsory education is commonly understood to take place in nested, structured institutions (Giddens, 1984) - individuals within classes within grades within schools within school districts within states and/or government departments. That is how modern, organized, state-funded education was designed to be, paralleling other $20^{\text {th }}$ century governance structures for UK public systems such as health and policing. This conception of scale is arguably too simplistic for understanding educational processes and systems This paper aims to answer two related questions: how should scale be understood and what difference would scale-thinking make for education research? These questions will be explored by drawing on various scholarly traditions from the study of ecosystems and human geography in order to develop some thinking around multi-scale methodology. As can be seen from the two quotes above, there are contrasting positions on the issue of scale. These are rooted in sometimes antagonistic scientific traditions and this article will work with, and between, these various positions in order to problematise the scale in education research.

In contrast to traditionally structured public systems like education, the geographies of the market are arguably harder to pin down, being more networked, unregulated and self-organizing. Indeed, the increasing marketization of education in recent decades has resulted in a noticeable drift from this traditional 'Russian doll' (Herod, 2011) metaphor of educational systems to a more complex set of relationships and spatialities as Stephen Ball (2007; Ball \& Exley, 2010) has highlighted. In the UK the current coalition government is working hard to implement its 'Big Society' vision by redefining relationships and positions within a range of these public-private spaces. This article is not primarily concerned with the shifting political landscape of education in England, or the emergence of public-private partnerships, other than to say that the spatial conceptual framework of this article could be usefully brought to bear on understanding those changes. Neither am I directly concerned here with changes over time, although it is important to emphasise that time is a critical dimension of the multi-scale thinking that this article explores, and, all too often, the failure to understand how imbricated educative processes occur over very different timescales (Lemke, 2000) hampers research and policymaking (Noyes, Drake, et al., 2011, under review).

My aim here is to problematize, and to begin to develop, some ideas around multi-scale research practice, grounding the following discussion in a critique of a study that I recently directed. The focus is therefore more on the methodological problems of multi-scale approaches, although these need to be considered in parallel with the interrelated issues of epistemology and ontology (Crotty, 1998). During the four years over which that project was designed, conducted and reported, new ways of thinking about the spatial 
conceptual framework of the study were developed, changing my perspective on this and similar projects, and also raising questions about the limitations of the study. The project was concerned with mathematical participation at upper secondary school level (14-18 year olds) and although I will refer to some of the findings for illustrative purposes, my use of the study is to contextualise the methodological and theoretical discussion; no particular knowledge, or interest in mathematics education is required. Nevertheless, I will take the time here to introduce the project and will give a flavour of the data collected and modes of representation later on.

The ESRC-funded Geographies of Mathematical Attainment and Participation (GMAP) project was a mixedmethods study that sought to understand the socially differentiated formation of learner trajectories in 1419 mathematics education. Through a combination of multilevel modelling (Goldstein, 2003) of performance data from the Department for Education's National Pupil Database, large student surveys in sixteen schools, cohort tracking and focus group interviews, the project explored the motivations of young people towards mathematical study and how schools, families and peers impact upon learner trajectories. Building on previous case study research on the learning trajectories of 10-12 year olds which theorized the socially differentiating power of schooling (Noyes, 2006), the GMAP project extended this work to older students. By investigating the impact of peers, classes, schools and neighbourhoods on learners' attainment and participation the study aimed to work on large and complex datasets, findings from which might prove more compelling to policymakers. Given my feel for the game at the time of planning the study, namely that to 'speak truth to power', or at least to policymakers and their representatives, researchers needed to use "the language of politics and persuasion" (Dorling \& Simpson, 1999, p. 1) this study intentionally included large scale statistical data collection and analysis. However, following Bourdieu's $(1998$, p. 2) argument that "the deepest logic of the social world can be grasped only if one plunges into the particularity of an empirical reality" I also wanted to work close-up on in depth case studies. In addition to identifying social trends I was also keen to offer convincing explanations of why these might be occurring and therefore what interventions might be more successful. It was therefore important for the design to collect data at both micro and macro scales and the 'naturally' occurring intermediate scales of classrooms, schools and neighbourhoods. There was a considerable degree of tension in thinking and working in this scaled way, engaging in paradigmbridging work, particularly when one has a predilection for particular scale of methods (Noyes, 2010). It might be that the problems of scale discussed in this paper are a product of this selection of methods, with different histories and framing epistemologies. However, this was my starting point and the range of methods reflects the diversity of approaches used to research many educational problems. Although my focus here is within one study, the question of how research that is conducted at different scales, with different methodological and epistemological frameworks, can be brought together in productive ways is a 
more general problem that is worth considering. I will return to this issue in the discussion on ecosystem research below.

The design for the study was deeply influenced by Bourdieu's (1977) theory of practice. Bourdieu's developed his field-habitus dialectic to make sense of social reproduction and to critique the general social stasis that tends to maintain inequitable power structures. He was keen to move beyond the agencystructure debates that had hampered social science and a similar concern can be seen in Giddens' aim to bring the micro/social and macro/system together. Both argued for continually produced and reproduced social structures, in both an objective sense and as embodied structure, structure made flesh, either in terms of the dispositions of the habitus (Bourdieu) or "as memory traces and as instantiated...social practices" (Giddens, 1984, p. 25). This sense of holding the micro and macro together was precisely the concern of the GMAP study; how to think and present 'agency-structure' research without ending up in the small-scale (much use of Bourdieu in education has overemphasised habitus) or the large-scale statistical studies (which do not connect to any scaled reality at the level of school, neighbourhood, classroom). As Giddens explains:

The basic domain of study of the social sciences...is neither the experience of the individual actor, nor the existence of any form of social totality but social practices ordered both over space and time (p.2)

In the work of both of these sociologists the scaled relationships of social space are writ large and such concerns were operationalized in the GMAP study as seen in the following research questions:

1. What are the patterns of attainment in secondary mathematics (at age 16) and enrolment and attainment in A level mathematics (post-16)?

2. Where is attainment/enrolment lower or higher than might be expected?

3. How do these patterns get structured in the daily educational and social practices at the level of the individual, peer group, school, neighbourhood and region?

The ontological and epistemological problems of scale, how scales interact with one another and how such multi-scale research could be designed, analysed and reported were at best only partially resolved at the design stage and continue(d) to be interesting theoretical and methodological questions. Figure 1 is a representation of the scales that formed the design of the study. These are useful to a degree but in this form are too flat, tidy, reductive and fixed. Fixing such a 'map' on a 2-dimensional sheet of paper is a problem common to all maps, as Massey $(2005$, p. 106) explains: "a map of a geography is no more that geography - or that space - than a painting of a pipe is a pipe". But this is true of all research whether text, 
statistics or diagrams; they are only ever representations. Figure 1 highlights scales of research activity, examples of processes and the methods employed at each of those levels.

Figure 1: schema for settings of interaction of interest in the GMAP project

The design of the study was based around several locales, or settings of interaction (Giddens, 1984) which comprise the organisational units of educational systems, e.g. classroom and schools. However, identifying meaningful locales (e.g. family, peer group, neighbourhood) on the right hand side of the Figure 1 is not so easy, even at the level of family. Some students can draw on complex networks of family and friends to support their educational work whilst another's social and cultural capital resources are either limited, in the sense that they are of limited value in scholastic exchange, or remain largely untapped. The project's starting point of nested levels within the education system is not without difficulty. This structural laminate representation echoes the Euclidean curricular geometries critiqued in the work of Davis and Sumara (2000) in which they used fractal metaphors from complexity theory to explain how everything from an interaction in a lesson to a unit of work is similarly complex, patterned and irreducible to simple, basic constituents. This idea of fractal geometry, in which social patterns might be scale-independent is not developed here but there is some connection to Bourdieu's work, for example, in his description of the habitus as both a 'structured structure' and a 'structuring structure' (Bourdieu, 1984). The development of these ideas during the project precipitated the first cracks in the model, hints of serious theoretical contradictions within the conceptual framework which are rooted in the limitations of using physical metaphors for explaining social life. If in observing/researching one social or educational locale the researcher is simultaneously observing the impact of structuration at multiple spatial and temporal social scales, the tidy, nested hierarchal model begins to look rather strained. In order to illustrate this consider the following vignette.

It's mid-May and a researcher is observing a group of students working on a mathematics task. These six students, part of a class of 30, have been taught by the same teachers throughout their school career. They are about to move schools and are being drilled to prepare for the imminent national tests for 11 year olds. This test will a) determine which ability group they are placed in for the first year of secondary school b) be reported, aggregated with other students in the year, to parents, Ofsted and included in league tables (for school and school district), c) contribute to whether the government meets its published targets for primary school attainment. The rationale for the test, the 'standards agenda', is motivated in part by international comparisons such as TIMSS ${ }^{1}$. One of these students, Edward, has a scholarship to the local selective boys' high

\footnotetext{
${ }^{1}$ Trends in International Mathematics and Science Survey
} 
school for next year whilst Stacey records in a video diary "I know what everyone thinks, that I am the dumbest kid in the class" (Noyes, 2004b). Matt and Marie are the most able mathematically (Noyes, 2006). Matt, the popular captain of the school football team is later scouted for the youth squad of the famous local club whilst Marie, who lives with her mum in an area notorious for various activities does not complete school. These four children live within a mile of one another but are socially distanced.

Although the researcher is physically situated within the locale of the classroom, multiple socio-educational scales - spatial and temporal - are present, with varying degrees of visibility, and are overlaid and entangled in complex ways. Lefebvre (1991) highlights the benefits of seeing space as hypercomplex, explaining that "the principle of the interpenetration and superimposition of social spaces...means that each fragment of space subjected to analysis masks not only one social relationship but a host of them that analysis could potentially disclose" (p. 88). This vignette hides the reflexive work needed by the researcher to minimise the impact of another set of positionalities (academic, white, male, etc.) brought to bear when making sense of this context. Certain features of the socio-scape are more clearly visible in this locale (e.g. teaching and learning), whereas others require more analytic work, but to ignore the influence of each of the scales would severely limit the veracity of any interpretation. Here the classroom is, following Bourdieu, both a 'structured structure' and a 'structuring structure', reproducing the very social differences - local, national and international - that produced it. And the multi-scalar nature of this context is temporal as well as spatial. The family/student trajectories, class sizes and policy trends operate over different time periods often giving these scales the appearance of permanence, of ontological reality, whereas in fact they are not fixed, given or absolute. Post-structural human geographies of space are helpful here. If space is understood as "the sphere of a multiplicity of trajectories" or "a simultaneity of stories so far" (Massey, 2005 , pp. 119,130 ) then the lesson is a window onto a set if intersecting social journeys, embodying social histories and signposting probable future directions. I will consider these ideas below.

So, to return to the opening quote from Hay (2005), there is a need for trying to understand complex socialeducation processes (time) and patterns (space) through a multi-scale approach although it is not clear what conceptualisations of space/scale might be most useful, theoretically and methodologically. A multi-scale methodology presumes the use of multiple or mixed methods. However, mixed-methods studies do not aim to make theoretical sense of the spatiality that is implicated in their designs. In sum, the initial theoretical and methodological goal of the GMAP project included developing integrated understanding of various processes and patterns that were presumably best observed and understood at different scales, what is elsewhere called 'scale bridging' (Berkes, Reid, et al., 2006; Hay, 2005; Willbanks, 2004). This would offer more robust explanations of social trends and could increase the usefulness of research, assuming of course 
that research might have some utilitarian (preferably emancipatory) purpose. Thinking about the use value of the research also raises some problems, particularly regarding how to analyse and report such multi-scale work. The typical length of journal papers means that one can simply work at any scale within the dataset and ignore the more challenging and interesting conceptual work between scales, or at most link two of the scales.

\section{A GMAP 'core sample’}

Before working into the literature relevant to my discussion here I offer a flavour of the kinds of data representations from the GMAP study. Given that this is merely for illustrative purposes, and for thinking with, it is necessarily partial and there is no attempt made here to present detailed methodological and validation processes, carefully constructed statistical models and rich qualitative accounts of learners and learning. This work can be found through the references elsewhere in this paper.

In calling it a 'core sample' I am falling back to the geographical/geological laminar metaphors that formed the original conceptual framework. Figure 2 is organised through the scales, although the earlier point about all scales being embedded through each scale should be borne in mind. All of the representations have an inherent spatiality, whether positioning schools in relations to one another or to the communities in which they are situated, positioning classes on a scale and even positioning Tom in brackets [a secondary voice to that of the researchers]. Each of these forms fixes differences which are not fixed, stable or reducible in such simple ways, as Massey warns. Nevertheless, given the limitations of flat representations they have something to offer.

Early in the study, and in keeping with the Russian doll style conceptual framework of nested locales, the idea of 'zooming into/out of' the data was something that I was aiming to do, rather as one would do with an online map. This is reflected in the way that I have organised Figure 2. As one navigates through the scales so certain features become more or less important and visible. At some scales on online maps, places get named and come into focus. At other scales features of the map are barely noticeable. I took this, rather uncritically, as a useful metaphor for the GMAP design and envisaged that the data would lead to this kind of complex map of data through which the researcher could zoom, seeing certain social patterns, processes and features appearing and disappearing are various levels of granularity. In light of the classroom vignette above I no longer think this is desirable, but the idea remains an appealing one, at the very least in how you might build explorable datasets which allow one to investigate social relationships across scales in a dynamic way.

Figure 2: Example of data representations at scales 


\section{Landscapes and ecosystems}

My interest in scale is part of an ongoing concern which began ${ }^{2}$ within a theorisation of 'learning landscapes' which was my earliest attempt to wrestle with these issues (Noyes, 2004a). In that piece I argued that the metaphors of geology, climate, human impact and time were important factors in understanding how education worked to impact learning. Although that analysis was somewhat oversimplified - a point that was helpfully made by a geographer who read that paper- it did begin to explore these dimensions of time and space. I want to begin this more in depth consideration of the notion of space and scale in modern geographic thinking by turning to ecosystems and urban studies, where notions of scale have been discussed in ways that might be of relevance to education research, particularly those interested in studies akin to the GMAP project.

There is a large literature in ecology studies that takes up the issues of scale. Scholars in urban dynamics (e.g. Batty, 2003), rural studies (e.g. Paquette \& Domon, 2003), development studies (e.g. Gray, 1999) and climate studies (e.g. O'Brien, Sygna, et al., 2004) take up the notion of multiple scales to investigate the impact of change and how it is understood and experienced at various scales of human activity. O'Brien et al explore the potential impact of climate change on Norway and note that although the country is generally in a good position regarding the potential vagaries of climate change, some areas will suffer the ill effects of climate change much more dramatically than others. Just considering aggregate effects is unhelpful for those in that position. Batty explains that:

"at an aggregative enough scale, all the volatility and dynamism of land use change in the city is ironed out, smoothed away. When we dig under this surface, this apparent equilibrium is far from being the stable and well-behaved system that we once assumed." (Batty, 2003, p. 1)

Similar principles would apply to studies of schools, in particular the reduction of such complex organisations to a few numbers, for example in an Ofsted grade or league table position. As an example of this in the GMAP project, surveys of 11 year olds showed high proportions of students disliking maths (Noyes, 2011, under review), echoing the findings of the Trends in International Mathematics and Science Survey (Sturman, Ruddock, et al., 2007). However, on closer inspection some differences between schools can be seen, and, as might be expected, there is much greater differences between classes within schools. Similar findings are replicated across school effectiveness studies, highlighting that within school variation is often greater than between school variation (Nye, Konstantopoulos, et al., 2004; Opdenakker, Van Damme, et al., 2002). This highlights the problem of overemphasising one scale, i.e. the school, for understanding education processes thus smoothing out very real local variation. Government tells us that 'standards' are

\footnotetext{
${ }^{2}$ Actually, this disposition towards a geographical spatialising of the world is rooted in my own habitus inherited from geographers and so is, in a sense probably deeper than I can properly comprehend
} 
rising in mathematics, but studies suggest that the between-school, and more importantly between-class (or teacher) differences are still considerable. Findings from the GMAP study suggest how influential one teacher is (Noyes, 2011, in press; Noyes \& Sealey, 2010). I am trying to avoid the structuralist assumption that effects are top down and this concern is at the heart of some of the post-structural critiques of scale. However, using complexity theory and the well-known butterfly effect the argument can be made that big effects originate from small perturbations at the local level. The logical extension of this being that large scale systems are the result of many small changes, although there is not space here to consider notions of methodological/ontological individualism. The best way forward here is to take a 'both and' rather than an 'either or' position, which is what Bourdieu and Giddens advocate. Nevertheless, the problem of building understanding across scales remains.

"it is now widely recognised that landscapes are complex systems composed of multiscale hierarchically organized entities that interact with spatial and temporal scales. These interactions result in scale-dependent spatial patterns that visually change, depending upon their scale of observation" (Hay \& Marceau, 2004, p. 71)

Here Hay and Marceau repeat the earlier point made in the context of the classroom vignette that education research at a particular scale will reveal certain kinds of patterns. Notably, their scales are physical realities organised in a hierarchical sense so the earlier problematization stands.

Ecologists who work with scale consider the grain and extent, namely the scale at which measurements are taken and the coverage at that scale. So, for example, a case study of one student would have the same grain size as a collective case study of 30 students within one class but the extent is quite different. A study of a class, or of the 30 students within that class might have the same extent but a different grain size. It is not difficult to see how these pairs might yield different kinds of data and interpretations. In geographical sciences the scale problem is concerned with a) the most appropriate scale of analysis for any particular process and $b$ ) the means of effectively and efficiently working between multiple scales of analysis, i.e. scalebridging.

Recently, the Millenium Ecosystem Assessment project explicitly aimed to connect research across scales to better understand the changing nature and impact of global ecosystems. It purposefully attended to "local community, watershed, national, regional - in addition to the global scale" (Hay, 2005, p. 250) and considered traditional knowledge and scientific information. However, as Hay acknowledges integrating these different epistemological positions or ways of knowing the world presents significant theoretical and methodological challenges. This is particularly challenging when bringing together the indigenous knowledges of, for example, weather and climate, with large-scale mathematical models. Clearly both 
knowledges have some merit, and it would seem sensible to combine these knowledges somehow but the means of doing this is not always clear. Similarly, in education research, the disconnections between student's knowledge and that of the teacher, researcher, policymaker, and so on, are well known and there has been limited success at combining these knowledges in a productive way. I am arguing here that this is in part a problem of scale.

Elsewhere in this literature Willbanks (2004) uses the term mosaics to describe the units at a particular scale; in the context of education in the UK this might be Local Authorities, schools, classrooms, friendships groups and individuals. He draws a link between shorter term processes occurring at the small scale and longer term processes at the larger scale. This does not work in education, or in social life more generally, so here is another limitation of these physical metaphors for understanding social processes. In education, classroom practice is notably slow to change (Galton \& Hargreaves, 2002; Hodgen, Küchemann, et al., 2010) and the large scale policy decisions (in impact at least) are made quickly, although according to the 'adiabatic principle' outlined by Lemke (2000), there is often little effective interaction between processes occurring over considerably different timescales. However, having said that there is evidence that even this is not clear cut. It has been pointed out that the National Curriculum for England is very closely related to that of 100 years ago.

In this ecosystem literature methods are designed to work at particular scales, framed by particular epistemologies, and this has resonance for education research. The problem remains of how these scalerelated methods are connected, although mixed-methods researchers are developing approaches to this (Tashakkori \& Teddlie, 1998, 2010). 'Bottom up' and 'top down' analyses can lead to different conclusions with research not meeting in the middle. Finally, and very importantly for education research, Willbanks (ibid) points out that the choice of scale is not politically neutral, although without reflexivity the political motivations might remain obscured. I have already hinted at a political motivation in the GMAP project and the same principle is no doubt widespread in education research, although this claim would be contested.

\section{Scale in human geography}

Moving from the ecosystems research of physical geographers and scientists, I now turn to the scale debate in human geography to see how it can help in thinking about education research. There are two strands of thought in human geography that are of relevance here. The first is that of the political economic geographers (e.g. Henri Lefebvre, Neil Smith) who draw on Marxist traditions to critique the socio-spatial distribution of resources, employment opportunities, poverty etc. The second group are those following a post-structuralist tradition (e.g. Doreen Massey). More recently some scholars have tried to bridge these two traditions (for example, McKinnon, 2010), or rather, take the best from each to build a more inclusive 
sense of scale, in geographic thinking. There are ideas here that are of great relevance to the GMAP project and to education research in general.

The issue of whether scales actually exist has fuelled an ongoing debate (Herod, 2011; Jones, 1998; Thrift, 1995) between idealism, which considers scale to be an epistemological, sense-making idea for categorising and relating process and practices, and Marxist materialism, although in some aspects these traditions are agreed. For example, there is general consensus that scale, whether real or imagined, is not pre-existent but constructed and reconstructed over time in complex ways (Herod, 2011; McKinnon, 2010). Thinking in terms of education in the UK, the Local Authorities which have served and supported schools and teachers have increasingly mediated national policy, offering targeted support to schools whilst remaining accountable to government (Local Authorities get 'inspected' too). The latest education reform project, part of the small government/'Big Society' agenda is transforming the scalar linkages between schools and government in new and unpredictable ways, reducing the authority of the Local Authority. As new relationships and allegiances are formed so scales of activity shift. In recent years we have seen the emergence of Academies that are no longer related to their Local Authority; school federations that bring together a few local schools under one executive headteacher and instances of 'successful' schools sponsoring their less successful neighbours. In a quite different space the ubiquity of social networking amongst teenagers is reforming scales of peer relationships in ways that have implications for how schools and society works. These are examples of what Brenner calls "choreogeographies of social power and social struggle" (Brenner, 2001, p. 607), although the power in these two examples is exercised and distributed in very different ways.

The issue of power is the $11^{\text {th }}$ and final point in Brenner's attempt to clarify what he means by 'scalar structuration' and echoes Swyngedouw's (1997, p. 169) claim that scaled locales are "the embodiment of social relations of empowerment and disempowerment and the arena through and in which they operate". Point 5 in Brenner's list is very relevant to this current discussion and gets to the heart of the critique of the GMAP conceptual framework:

"The meaning, function, history and dynamics of any one geographical scale can only be grasped relationally, in terms of its upward, downward and sidewards links to other geographical scales situated within tangled scalar hierarchies and dispersed interscalar networks...Scale, therefore cannot be construed adequately as a system of territorial containers defined by absolute geographic size (a 'Russian dolls' model of scale)" (p. 605)

This emphasis on the relational, tangled nature of space and scale reflects the notion of hypercomplexity in Lefebvre (1991) although, as Brenner's critics (Marston \& Smith, 2001) point out, he reads too much into Lefebvre who actually had little to say about scale per se. Marston (2000), surveying the expanding 
literature on scale at the turn of the century, was concerned by the particular focus on capitalist production in discussions of scale and she made the case for a socially constructed scalar thinking incorporating social reproduction and consumption, in which the family and body are centrally important in the production of scale. Within a few years Marston et al (2005) were calling for a 'human geography without scale', due to the their perception of the conceptual damage being wreaked by the dominant hierarchical notions of scale that I referred to above.

More recently Moore (2008) has rejected Marston et al's call for a 'flat ontology' of scale as throwing the baby out with the bathwater. He points out that in the debates surrounding scale in human geography there has been a failure to distinguish between scale as a category of practice and of analysis and that the latter has lead to fruitful but not always helpful theorising and debate. Importantly, Moore asserts that the primary concern is with making sense of practices which are distributed at different scales of activity. Such a concern resonates with the methodological questions that frame this paper. However, it does raise the issue of whether using scale as a category of analysis, which is what I am trying to do herein, is itself problematic.

The notion of a 'flat ontology' of scale aims to challenge the fixity of hierarchical metaphors in politicaleconomic discussions of scale in human geography. Although most people in the debate agree that scale is not pre-existent but socially constructed, the hierarchical scalar models, according to Marston et al (2005) privilege the 'global' as the arbiter of power rather than the local, the family, the individual agent. In other words, these conceptions of scale privilege structure over agency. At its base, this is the same argument that has been rehearsed throughout the social sciences over the last century and to which Bourdieu and Giddens addressed their theoretical tools, with the goal of seeing agency and structure as mutually constitutive, shifting but probabilistically tending to reproduction.

Recently, McKinnow (2010) has also sought to work between the positions of the poststructuralist and political-economic geographers. He acknowledges the value in seeing space and scale as fluid connections, networks and relations, as in the work of Massey, but cautions against "divorcing discourse and performativity from material dimensions of scale" (p. 22). It seems that the objection to the apparent fixity of scale in political-economic conceptions of scale might be softened with some consideration of time which is notably and strangely absent from much of the geographers' deliberations of scale. McKinnow diplomatically asserts that

The political-economic and poststructural perspectives can be seen to offer complementary insights into the construction of scale, focusing attention on processes of material production and capitalist restructuring, on the one hand, and social practice and discourse on the other ( $p$. 28) 
This helpful middle way, the 'both and' option, opens up the possibility of taking some of this thinking from human geography and usefully working with it in the context of the particular problems of education research. In the context outlined in the GMAP study there is clearly little benefit in denying one sense of the scalar reality of classrooms (although clearly they are not fixed, but shifting in size, composition, modes of interaction, etc, depending on when and where you look at them) but taking McKinnow's position, one of cross-fertilization rather than theoretical integration, offers a promising way forwards. That said, my classroom vignette outlined earlier highlights the error that researchers could fall into if they ignored multiple socio-spatial and temporal process twisted through lessons or other studies.

\section{Multi-scale methodology for educational research: possibilities and problems}

This survey of scholarly work across ecosystem research and human geography offers a range of useful tools for thinking about scale, and parallels a series of debates that have smouldered across the social sciences over the years. One of the challenges common to geographers and educationalists, is that of thinking physically and socially at the same time. Public education can be thought of as being politically organised in areal terms: a country is divided into states/regions, school districts/local authorities, school catchments, classrooms, and so on. But this does not take into account the socio-spatial patterns of relationships which intersect these divisions of schooling, which have, and continue to be, reformed.

In the ecosystems literature a number of useful ideas appear that have parallels or applications in education research. They argue that phenomena are scale dependent: for example, life histories to not expose the extent of social inequalities any more than statistical surveys help us to understand learning psychology. Research at one scale can all too easily smooth turbulence and ignore significance at a lower level of granularity, or fail to recognise itself as the turbulence of a higher level of granularity. Research that is upscaled or downscaled, i.e. when research from one scale is used to generalise or conjecture to another scale, does not always meet in the middle. This suggests that systems research needs to be conducted at different scales and carefully integrated. Another challenge that researchers on the MA project have considered is the status of knowledge held by people/groups acting at various scales, the nature of this knowledge (indigenous/scientific, traditional/statistical, amateur/professional, etc), and how to build a more comprehensive knowledge base by judiciously combining these knowledges. Although areas of education research attempt to bridge similarly dispersed education knowledges this could be done in a more systematic way. This notion of scale-bridging or paradigm-bridging, with the goal of building better understandings of social/educational phenomena by incorporating multiple modes and scales of knowledge, is a helpful idea. However, I am not here suggesting particular approaches for doing this kind of bridging.

From the human geographers we get the constructivist notions of social space as fluid, multiple, becoming, not so much hierarchical as networked. The notion of spatial hypercomplexity has resonance for education 
researchers seeking to understand complex systems. Although scale is not central to the theses of these spatial geographers there is a vigorous debate about the theory and implications of scalar thinking in social science. Central to this tradition of scholarship are concerns about the unequal distribution of power, an idea that was core to Bourdieu's notion of field. Although the point regarding the confusion between scale as a category of practice and analysis is helpful it seems that both of these are of value in education theorising and methodology. This human geography tradition explains how multiple social and temporal scales that can be 'seen' at any level, assuming appropriate critical analysis.

The problem of thinking space and scale as simultaneously physical and social goes to the heart of the challenges facing the GMAP project. Such a problem might be approached with some of these theoretical and methodological tools developed in different geographic traditions. My earlier classroom vignette highlights the tensions between educational proximity and social distance. It is easy to see how this works in one sphere of activity, namely the classroom. It is also easy to see how analyses of schools made without due attention to classrooms and to individual's lives - most of which happen outside of schools - smoothes out the local detail, which is not simply social 'white noise' but evidence - the 'empirical reality'- of the dialectical relations between micro and macro; the complex interactions between national policy, historical modes of teacher professionalism, deep cultural dispositions to learning, etc and all of which is embodied/embedded in the individuals, practices, objects and structures of daily lives, schools, policies, etc.

However, the problem of researching between, and representing, the large scale statistical analyses and the fine grain individual interviews remains challenging and here the ecosystems scholars have experienced similar problems. Small scale does not imply little value, just as large scale does not imply high value, although not everyone would agree in terms of research funding ${ }^{3}$. Scale bridging is no doubt a challenge facing education research: connecting very different data scales might offer powerful new ways of bridging paradigms and scales of activity. It might also help to develop a more robust range of evidence, understandings and impacts. As in the MA project, connecting the lone qualitative researcher (knowledgeable local) with the large teams producing statistical reports for ministers, review panels, think tanks, etc., is an ongoing challenge.

In Bourdieu's (2004) critique of the scientific field he describes the 'structural interlockings' between scientist, lab, groups of labs, etc and such a notion of structural interlocking is helpful for investigating education systems. There is an apparent freedom at any particular scale but this is always locked into, in varying degrees, the broader social arrangements and distributions of power. An education research methodology which paid more strategic attention to these interlockings would be beneficial. However,

\footnotetext{
${ }^{3}$ The Economic and Social Research Council recently scrapped its small grants scheme and increased the upper limit for the main grants with the intention of production larger studies with greater social impact.
} 
there are three important issues that the field would need to consider and address in order to strengthen its collective capacity to do this kind of multi-scale work.

Firstly, there is a need to develop education specific theories and analyses of scale, alongside more sustained interdisciplinary attention to the problems of scale and space in social science research. Close readings of, and conversations with the geographers who have explored these concerns would be a good place to start and hopefully this paper makes a contribution to this work. Secondly, part of this scalar thinking needs to be focused on the problem of time. In another recent project we evaluated the design and piloting of a major national programme of curriculum and assessment developments for 14-19 year olds in mathematics. Some of the least well considered, and potentially most problematic aspects of such pilots are the multiple timescales which need to dovetail together for success (Noyes, et al., 2011, under review). However, the temporal problem goes beyond careful timetabling and project management. A more sophisticated understanding of the time scales involved in education, as outlined by Lemke (2000) and highlighted in the earlier vignette, would help educators, researchers and policymakers to make better choices. Thirdly, there is a need to diversify forms of representation and modes of research communication to enable the kinds of mixed-paradigm, multi-scale methods to be integrated with integrity. This is important both for the processes and products of research. As new forms of representation become more common this enables research to think in different ways, even to the extent of imagining different questions and approaches to investigating those questions.

The stimulus for this paper has been reflections on a methodology that was intended as multi-scale, but for which I had not fully appreciated the theoretical, methodological or representational complexity. Although the mixed-methods literature pays some attention to some of the methodological issues the challenge of theorizing, analysing and communicating research in terms of spatial and temporal scales remains. Moreover, given the spatial restructuring of society within regions and nations, as well as between nations, having a more considered understanding of scale might enable new analyses of problems in education practice and policymaking. Finally, in response to the charge that the scale problems discussed herein might be the result of the particular allegiance to certain mixed methods that were chosen at the start of this project, I can only agree - in part. It is clearly the case that the methods come from education research traditions that do not often intersect (e.g. school effectiveness, Bourdieusian case studies). However, the issues of scale are both practically and analytically pertinent, particularly at a time when either a) mixedmethods studies are increasingly desirable, or b) the separation of 'small scale' unfunded research from the statistical models that are often developed by governments, quangos and think tanks, outside of the tradition university-based research community. There is, as with the ecosystems researchers, a need to 
acknowledge the value of these differently scaled studies and the potential benefits that would accrue from sustained effort to bridge these scales.

\section{Acknowledgements}

This research was supported by the Economic and Social Research Council (RES-061-25-0035). I am also grateful to the anonymous reviewers and conference participants who commented on earlier versions of this paper.

\section{References}

Ball, S. (2007). Education plc. London: RoutledgeFalmer.

Ball, S., \& Exley, S. (2010). Making policy with 'good ideas': policy networks and the 'intellectuals' of New Labour. Journal of Education Policy, 25(2), 151-169.

Batty, M. (2003). Agents, cells and cities, new representational models for simulating multi-scale urban dynamics. Centre for Advanced Spatial Analysis, UCL.

Berkes, F., Reid, W., Wilbanks, T., \& Capistrano, D. (2006). Conclusions: bridging scales and knowledge systems. In W. Reid, F. Berkes, T. Wilbanks \& D. Capistrano (Eds.), Bridging Scales and Knowledge Systems: concepts and applications in ecosystems assessment (pp. 315-331). London: Island Press. Bourdieu, P. (1977). Outline of a Theory of Practice. Cambridge: Cambridge University Press. Bourdieu, P. (1984). Distinction: a social critique of the judgement of taste. Cambridge, MA: Harvard University Press.

Bourdieu, P. (1998). Practical Reason. Cambridge: Polity Press.

Bourdieu, P. (2004). Science of Science and Reflexivity. Chicago: The University of Chicago Press.

Brenner, N. (2001). The limits to scale? Methodological reflections on scalar structuration. Progress in Human Geography, 25(4), 591-614.

Crotty, M. (1998). The Foundations of Social Research. London: Sage.

Davis, B., \& Sumara, D. (2000). Curriculum Forms: on the assumed shapes of knowing and knowledge. Journal of Curriculum Studies, 32(6), 821-845.

Dorling, D., \& Simpson, S. (1999). Introduction to statistics in society. In D. Dorling \& S. Simpson (Eds.), Statistics in Society: the arithmetic of politics (pp. 1-5). London: Arnold.

Galton, M., \& Hargreaves, L. (2002). Transfer: a future agenda. In L. Hargreaves \& M. Galton (Eds.), Transfer from the primary classroom: 20 years on (pp. 185-202). London: RoutledgeFalmer.

Giddens, A. (1984). The constitution of society. Cambridge: Polity Press.

Goldstein, H. (2003). Multilevel Statistical Models, 3rd Edition. London: Hodder Arnold.

Gray, L. C. (1999). Is land being degraded? A multi-scale investigation of landscape change in southwestern Burkina Faso. Land Degradation and Development, 10, 329-343. 
Hay, G. J. (2005). Bridging scales and epistemologies. International Journal of Applied Earth Observation and Geoinformation, 7, 249-252.

Hay, G. J., \& Marceau, D. J. (2004). Multiscale object-specific analysis (MOSA): an integrative approach for multiscale landscape analysis. In S. M. de Jong \& F. D. van der Meer (Eds.), Remote sensing and digital image analysis including the spatial domain (pp. 71-93). Dordrecht: Kluwer Academic Publishers.

Herod, A. (2011). Scale. London: Routlege.

Hodgen, J., Küchemann, D., Brown, M., \& Coe, R. (2010). Multiplicative Reasoning, Ratio and Decimals: A 30Year Comparison of Lower Secondary Students' Understandings. Paper presented the International Group for the Psychology of Mathematics, Belo Horizonte, Brazil.

Jones, K. (1998). Scale as epistemology. Political Geography, 17(1), 25-28.

Lefebvre, H. (1991). The production of space (D. Nicholson-Smith, Trans.). Oxford: Blackwell Publishing. Lemke, J. (2000). Across the scales of time: artifacts, activities and meanings in ecosocial systems. Mind, culture and activity, 7(4), 273-290.

Marston, S. (2000). The social construction of scale. Progress in Human Geography, 24(2), 219-242.

Marston, S., Jones, J. P., \& Woodward, K. (2005). Human geography without scale. Transations of the Institute of British Geographers, NS 30(416-32).

Marston, S., \& Smith, N. (2001). States, scales and households: limits to sclae thinking? A response to Brenner. Progress in Human Geography, 24(4), 615-619.

Massey, D. (2005). For space. London: Sage.

McKinnon, D. (2010). Reconstructing scale: towards a new scalar politics. Progress in Human Geography, 35(1), 25-36.

Moore, A. (2008). Rethinking scale as a geographical category: from analysis to practice. Progress in Human Geography, 32(2), 203-225.

Noyes, A. (2004a). Learning Landscapes. British Educational Research Journal, 30(1), 27-41.

Noyes, A. (2004b). Video diary: a method for exploring learning dispositions. Cambridge Journal of Education, 34(2), 193-209.

Noyes, A. (2006). School Transfer and the Diffraction of Learning Trajectories. Research Papers in Education, 21(1), 43-62.

Noyes, A. (2010). Researching with large datasets: learning to think big when small is beautiful In P. Thomson \& M. Walker (Eds.), The Routlege Doctoral Student's Companion (pp. 213-220). Abingdon: Routlege. Noyes, A. (2011, in press). Choosing Mathematics. Cambridge Journal of Education.

Noyes, A. (2011, under review). Student-centred teaching and the enjoyment of mathematics. Submitted to Research in Mathematics Education. 
Noyes, A., Drake, P., \& Wake, G. (2011, under review). Education reform and the scales of time: the case of England's 14-19 mathematics pathways.

Noyes, A., \& Sealey, P. (2010). Investigating participation in Advanced level mathematics: a study of student drop out Research Papers in Education (in press).

Nye, B., Konstantopoulos, S., \& Hedges, L. (2004). How large are teacher effects? Educational Evaluation and Policy Analysis, 26(3), 237-257.

O'Brien, K., Sygna, L., \& Haugen, J. E. (2004). Vulnerable or resilient? A multi-scale assessment of climate impacts and vulnerability in Norway. Climatic Change, 64, 193-225.

Opdenakker, M.-C., Van Damme, J., De Fraine, B., Landeghem, G., \& Onghena, P. (2002). The Effect of Schools and Classes on Mathematics Achievement. School Effectiveness and School Improvement, 13(4), 399-427.

Paquette, S., \& Domon, G. (2003). Changing ruralities, changing landscapes:exploring social recomposition using a multi-scale approach. Journal of Rural Studies, 19, 425-444.

Sturman, L., Ruddock, G., Burge, B., Styles, B., Lin, Y., \& Vappula, H. (2007). England's achievement in TIMSS 2007: National report for England. Slough: NFER.

Swyngedouw, E. (1997). Exclusing the other: the production of scale and scaled politics. In R. Lee \& J. Wills (Eds.), Geographies of economies (pp. 167-176). London: Arnold.

Tashakkori, A., \& Teddlie, C. (1998). Mixed Methodology: combining qualitative and quantitative approaches. Thousand Oaks, CA: Sage.

Tashakkori, A., \& Teddlie, C. (Eds.). (2010). Handbook of mixed methods in social and behavioural research (2nd ed.). London: Sage.

Thrift, N. (1995). A hyperactive world. In R. J. Johnston, P. Taylor \& M. Watts (Eds.), Geographies of global change: remapping the world in the late twentieth century (pp. 18-35). Oxford Blackwell.

Willbanks, T. J. (2004). How scale matters: some concepts and findings. Paper presented at the Bridging scales and epistemologies-linking local knowledge and global science in multi-scale assessments. from [http://www.maweb.org/documents/bridging/papers/Wilbanks.tom.pdf]. Last retrieved January 24, 2011. 